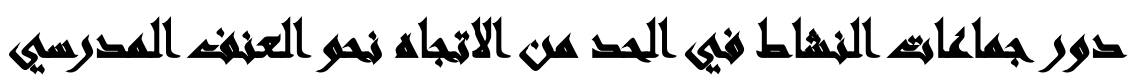

[v]

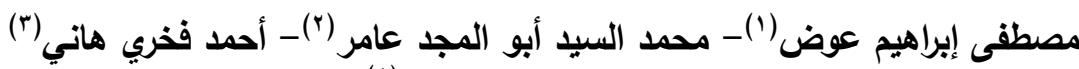

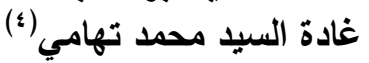

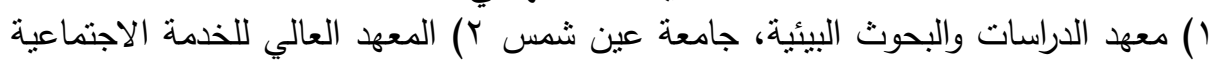

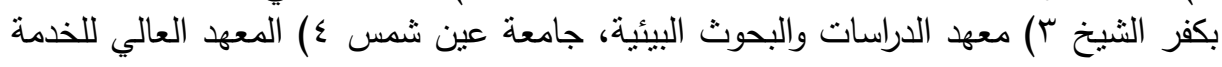

الاجتماعية ببنها

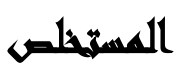

يستخلص من هذه الدراسة أن جماعات النشاط لها دور في الحد من الاتجاه نحو العنف

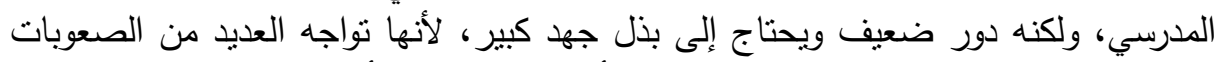

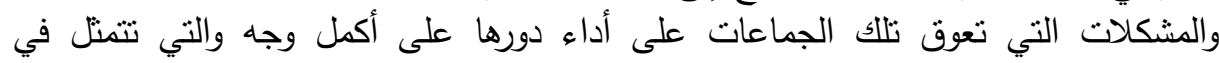

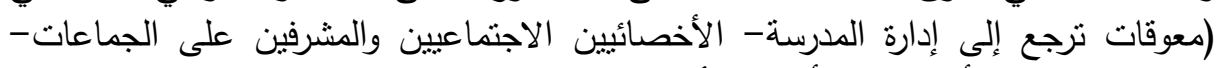

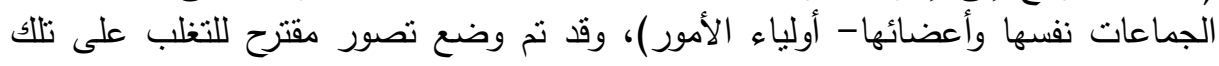

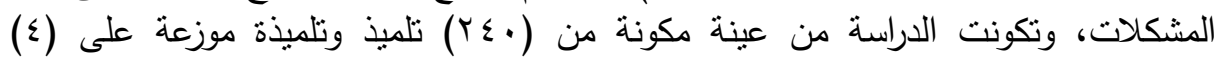

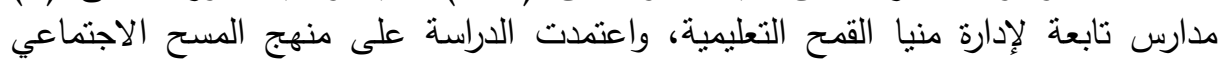

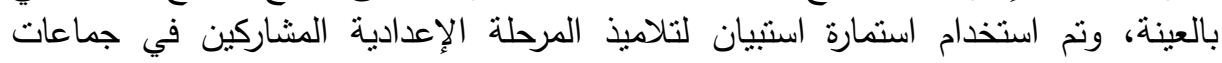

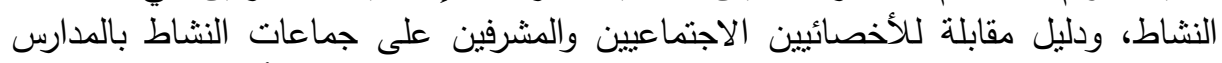

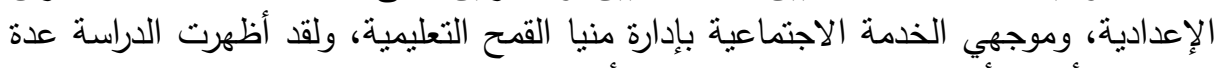

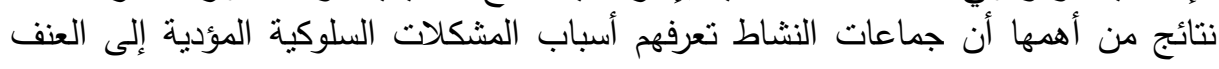

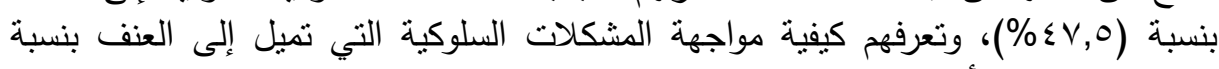
أوض)

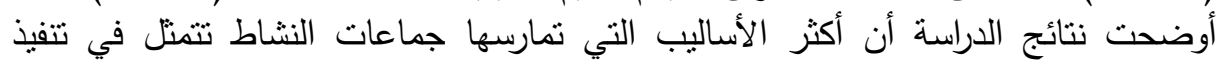

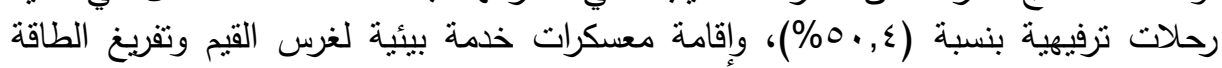

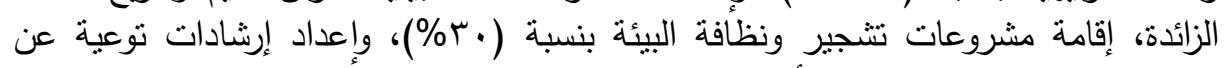

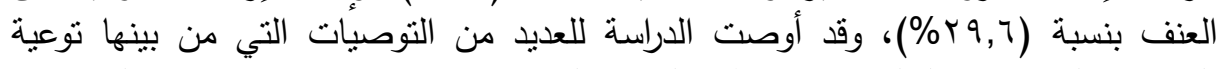

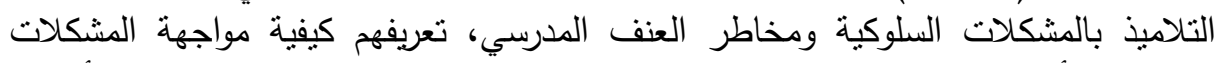

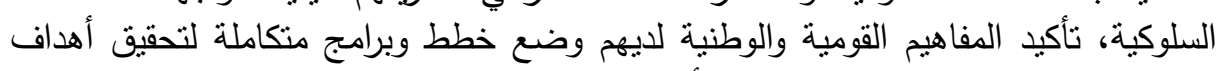

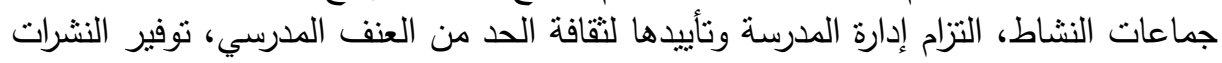
والكتيبات والكتب، التي تسهم في الحد من الاتجاه نحو العنف المدرسي لدى التهائلاميذ. 


\section{المهابs}

لا يكاد يخلو مجتمع معاصر من بعض أنثكال العنف، فقد أضحى أحد حقائق العصر ،

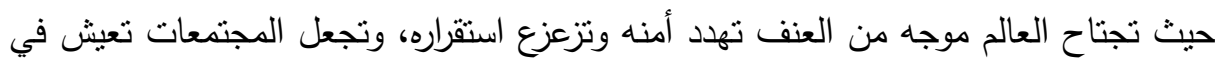
قلق وحيرة إزاء هذه الظاهرة التي بلغت أثندها في القرن الواحد والعشرين، الذي شهد أكثر أنثكال العنف نتوعًا، كما تميز بنقلة نوعية في النطور العلمي والتكنولوجي، الذي سخر في لهن

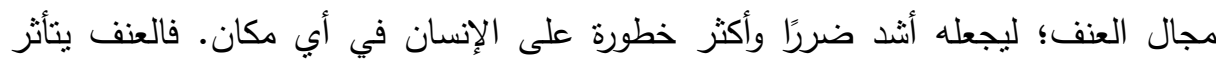
بالتقافة التي ينشأ ويمارس في ظلاها، ولقد انتشرت أعمال البلطجة بما يتضمنه من الإنسان فئل أحداث عنيفة بين تلاميذ المدارس الإعدادية في العديد من المتمعات، بما بستدعي الاهتمام بالجهود الخاصة بالوقاية من أعمال العنف (Unnever \& Cornell,2003, 2). ويمثل العنف بشكل عام جزءًا دائمًا من معاناة الإنسان ويمكن مشاهدة آثاره بأشكال مختلفة في شتى أنحاء العالم، إذ يفقد أكثر من مليون شخص حياتهم كما يعاني أكثر من ذللك بكثير من إصابات غير مميتة نتيجة للعنف الموجه للذات أو بين الأثخاص أو العنف

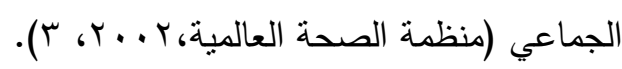

العنف قضية تاريخية وظاهرة العنف قديمة قدم البشرية ذاتها عندما حدث خلاف بين قابيل وهابيل انتهي بإن قتل إحدها الأخر .وبعد إن نطورات المجتمعات والثقافات تطورات

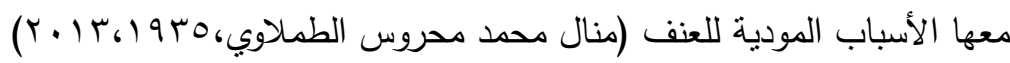
العنف كدد المشكلات السلوكية إصبحت تعاني منه كل المجتمعات حيث يمكن ملاحظته بكثره بين طلبه المدارس بشكل يومي فهي كظاهرة عالمية توجد في معظم الدول

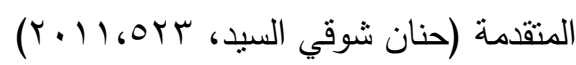

\section{(x)}

على الرغم من أن العنف أو التعرض للعنف أصبح اليوم موضوع اهتمام أساسي للآباء والمدرسين ومديري المدارس نتيجة لأن مشكلة التعرض للعنف لم تعد تحدث فقط في المنازل بل أيضًا في المدارس فإن العنف مازال في تزايد ملموس ضد أبنائنا سواء في بيوتتا أو 


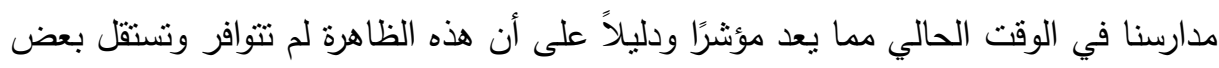

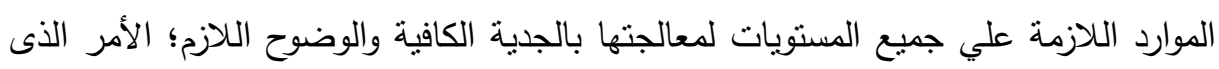
يقتضي منا كباحثين الاهتمام بنلك الظاهرة في محاولة للتعرف عليها بأنثكالها المختلفة

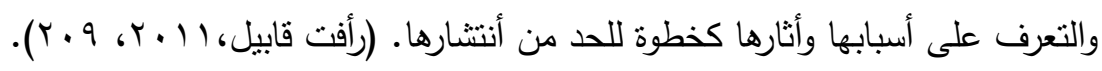
فلم يعد العنف المدرسي ظاهرة سلوكية مسيئة للمدرسة التي ينشب فيها التها العنف فحسب؛ وإنما تخطت ذللك إلى ترك أثر سلبي على المدارس الواقعة في محيطها (لويس

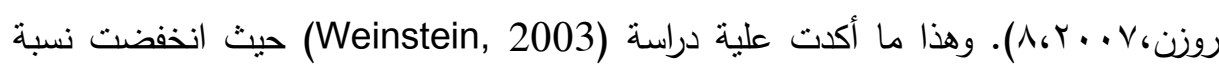

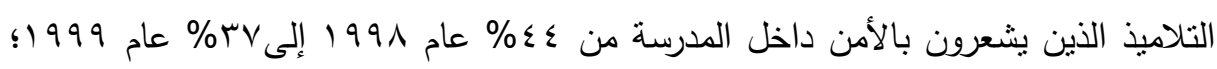

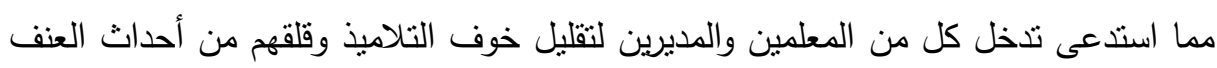
المنتشرة بين التلاميذ داخل المدرسة. تصنف مشكلة العنف المدرسي من ضمن المشكلات التي تتصل بالخلل بالنظام

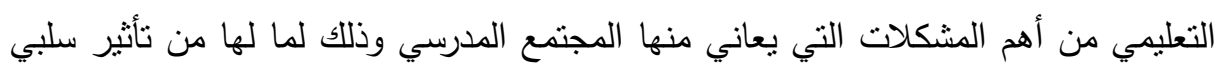
في حياه الطالب الدارسية.ولعل ذلك ما يجعل العنف المدرسي محل قلق وأهتمام المسئولين

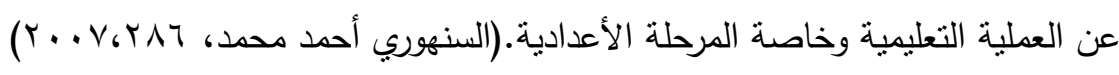
علاوة على ذلك توجد العديد من الدراسات التي تثير إلى انتشار العنف من أمنتلها

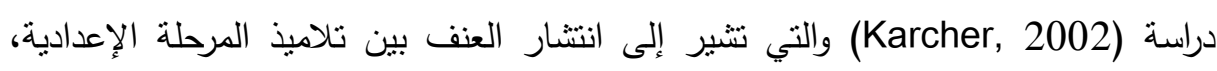
دراسة (Carney et al, 2005) والتي اهتمت بدراسة العنف والأمن داخل المدارس بشمال فلوريدا، ودراسة (Relationl \& Aggression, 2005) التي اهتصت بدارسة العدوان المتصل بالعلاقات بين التلاميذ، والتخفيف من حدته لدى التلاميذ الإناث بالمرحلة الإعدادية.

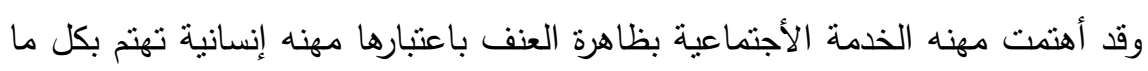

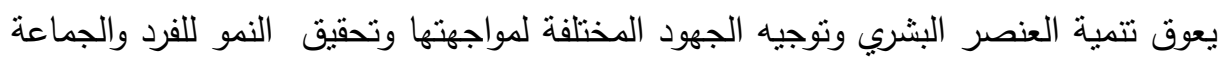

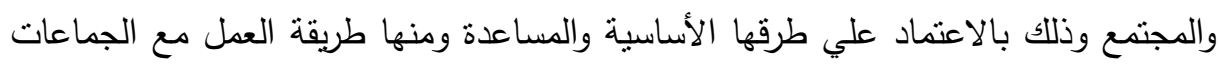

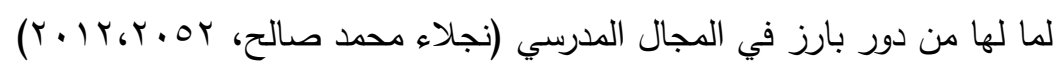


ويمكن القول بأن طريقة خدمة الجماعة، تعمل على زيادة الطاقة المبذولة في أثناء

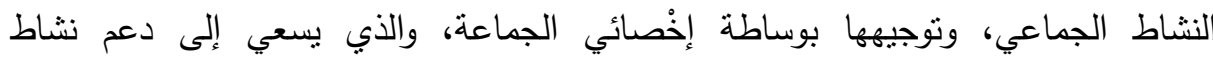

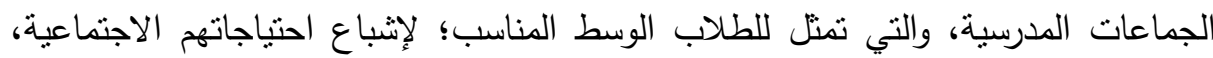

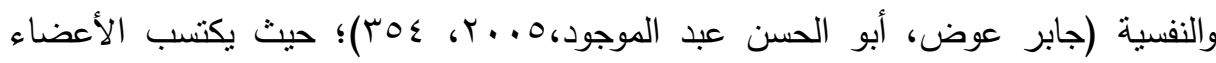
أنماطًا سلوكية، تتفق مع ثقافة المجتمع، وتنهم في - الوقت ذاته- في نموها، وتؤمن طريقة

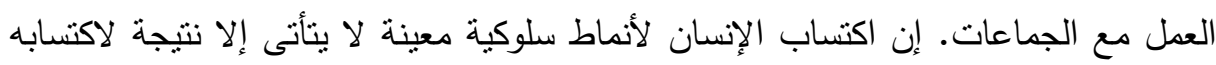

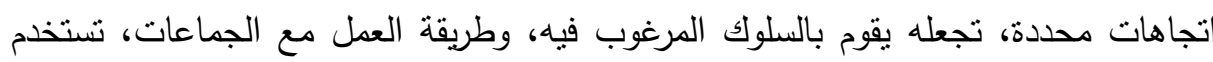

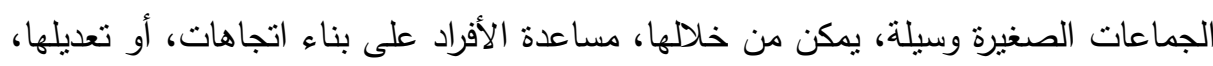

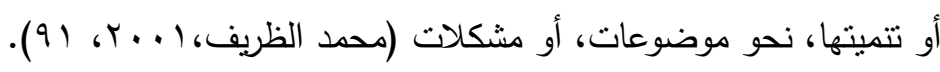

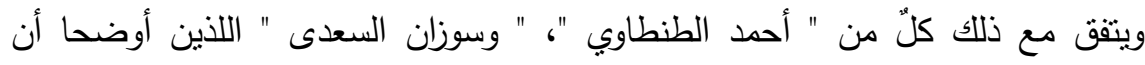
النشاط المدرسي، لا يقل أهمية عن الدرس داخل الفصل، حيث يعبر فيه التلاميذ عن ميولهم، ويشبعون رغباتهم، وحاجاتهم، ويسهمون إسهامًا فعالاً في تحقيق الأهداف العامة للتربية؛ لأن

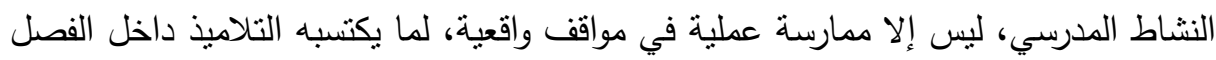
من العادات، والمهارات، والقدرات المختلفة، وتدريبهم على ممارسة المواقف الاجنماعية

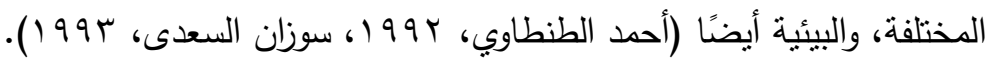

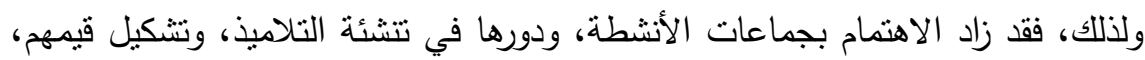
واتجاهاتهم، من منطلق أن جماعات النشاط بالمدارس، هي الجماعات المؤهلة؛ لتربية التلاميذ

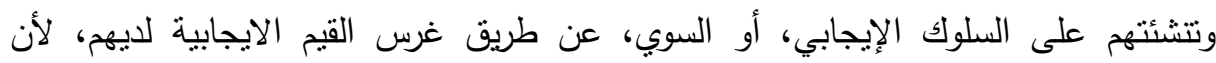
مشاركة التلاميذ في الأنشطة بشكل إيجابي، وفعال ينمي لايهم المعرفة، والوعي بمشكلة العنف. ونتيجة لتفثي سلوك العنف داخل المدارس المصرية لما له من أثز سلبي علي واقع من الانضباط المدرسي من ناحية والتحصيل الاكاديمي من ناحية أخري فقد صدر القرار رقم

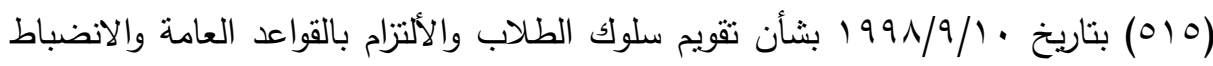




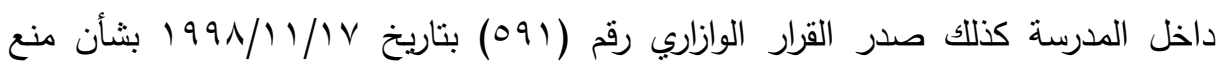
العنف في المدارس.

ومن خلال ما سبق، يتضح أن العنف، قضية مهمة من قضايا المجتمع العالمي والمحلي المعاصر ، حيث يؤثر على الأطفال بشكل عام وتلاميذ المرحلة الاعدادية، من خلال الانتماء إلى الجماعات المدرسية، التي تلعب بدورها على تتمية الوعي لديه تجاه بئنئنة

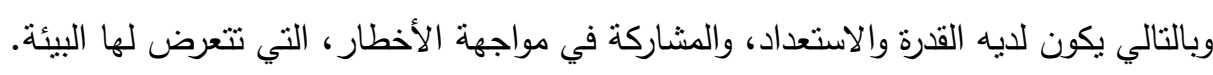

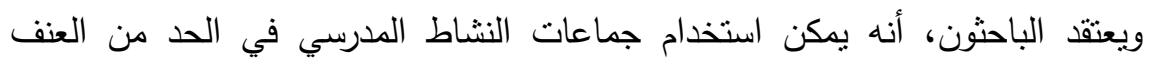

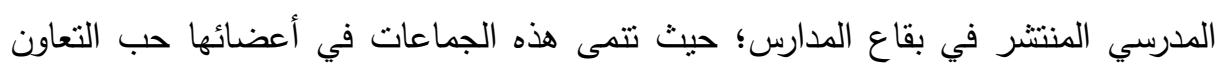

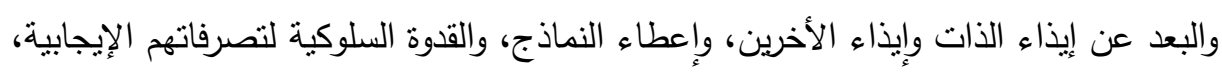

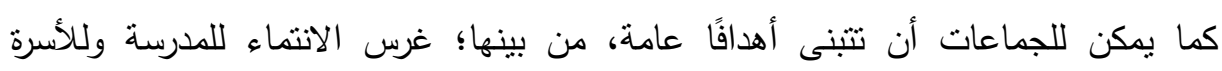
وللوطن بشكل عام بمساعدة الإخصائي، الذي يعمل معها.

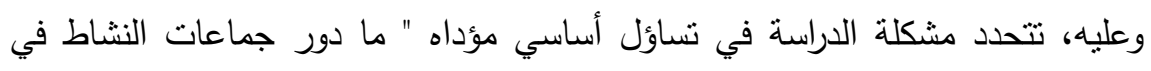
الحد من العنف المدرسي، من حيث طبيعة هذا الدور وصعوباته، ومدى نجاح هذه الجماعات

$$
\text { في الحد من العنف المدرسي؟ العنفي منئ }
$$

\section{تصاؤلايت الصواسمة}

تحاول الاراسة في إطار تحقيق أهداف الدراسة بالإجابة على عدة تساؤلات وهي:

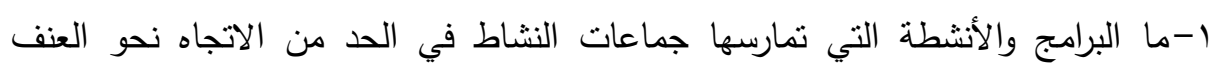

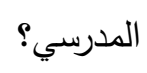

ץ-ما الوسائل التي تستخدمها جماعات النشاط في الحد من الاتجاه نحو العنف المدرسي؟

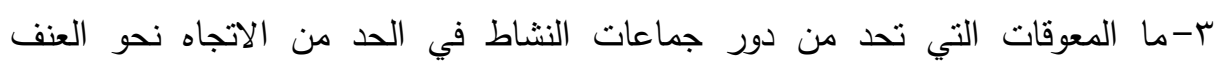

$$
\text { المدرسي؟ }
$$

ع-ما المقترحات للحد من المعوقات التي تحد من دور جماعات النشاط في الحد من الاتجاه

$$
\text { نحو العنف المدرسي؟ }
$$




\section{أهمي التصواسة}

1- الأهمية العلمية: وهي إثراء الدراسات المتعلقة بالعنف المدرسي وجماعات النشاط وذللك لتزايد الاهتمام بهذه الجماعات في المجال المدرسي. r-الأهمية التطبيقية: وهي معرفة دور جماعات النشاط في الحد من الاتجاه نحو العنف

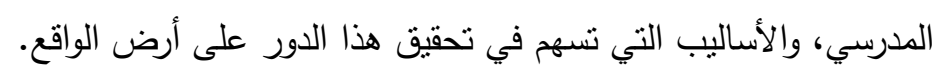

\section{أهساهي الشواسمة}

فالهدف الرئيسي الذي تسعى الدراسة إلى تحقيقه هو " التعرف على دور جماعات

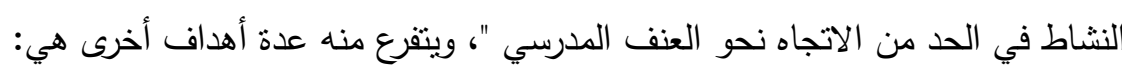

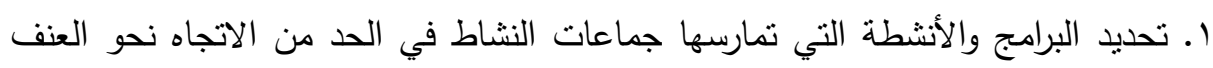
المدرسي. r. تحديد الوسائل التي تستخدمها جماعات النشاط في الحد من الاتجاه نحو العنف المدرسي. r. تحديد المعوقات التي تحد من دور جماعات النشاط في الحد من الاتجاه نحو العنف

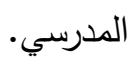

ء. وضع تصور مقترح لتعظيم دور جماعات النشاط في الحد من الاتجاه نحو العنف

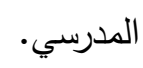

\section{مغخاهيه التوراسة}

1 - مفهوم الدور: يرى الباحثون أن الدور إجرائيًا هو عبارة عن " مجموعة من المهام،

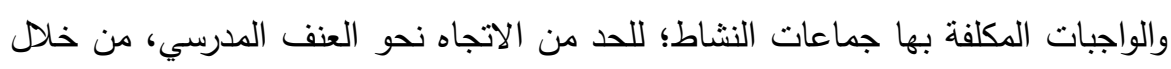
الأنشطة، والبرامج، والمشروعات، التي تمارسها داخل المدرسة، أو في محيطها، من خلال التهاه توجيه الإخصائي الاجتماعي، وفي ضوء الاعتبارات المهنية للخدمة الاجتماعية ". 
r - مفهوم جماعات النشاط: ويقصد بها الباحثون إجرائًا " الجماعات الاجتماعية المُشكلة داخل المدرسة ويشرف عليها الأخصائي الاجتماعي وهي (جماعة الخدمة العامة، جماعة الرحلات، جماعة الهلال الأحمر)".

ب- مفهوم العنف المدرسي: ويشير إليه الباحثون إجرائيًا أنه هو " كل سلوك عنيف الفهي

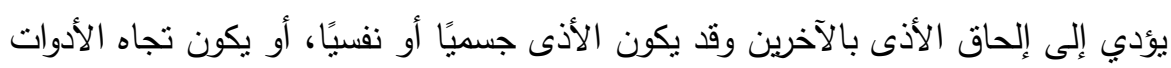

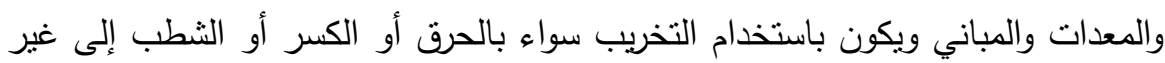

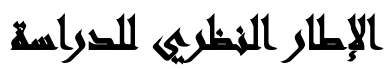

أولاً: العنف المدرسي: أصبح العنف من الظواهر الاجتماعية الخطيرة التي باتت واضحة على مرأى ومسمع الجميع مثل أي ظاهرة اجتماعية منتشرة والتي تعتبر من السلوكيات

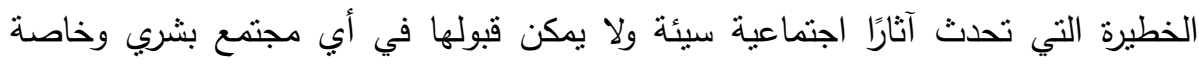
المجتمعات التي تمتاز بحضارة إنسانية راسخة اتسمت بالهدوء والاستقرار والقيم الروحية

$$
\text { والإسلامية. }
$$

1- أثنكال العنف: العنف الجسدي- العنف اللفظي - العنف الرمزي، وقد يأخذ العنف شكلين

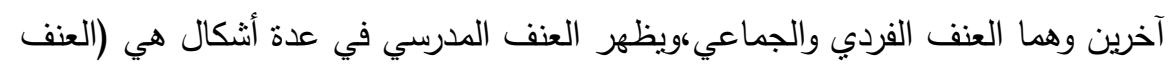

$$
\begin{aligned}
& \text { الجسدي - العنف النفسي -الاعتداء على الممتلكات). } \\
& \text { r- بآثار العنف المدرسي: }
\end{aligned}
$$

ا ـ الآثار نفسية ، يتزتب على سلوك العنف آثارٌ نفسية عديدة، كالثعور بالخوف والفزع، كما تظهر لديه نقص الثقة بالنفس والاكتئاب والتوتر، وكذلك عدم الإحساس بالأمان (فوزي

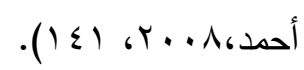

r. الآثار الاجتماعية، وتتمثل في الخمول الاجتماعي، حيث يفقد التلميذ المعنف من طرف

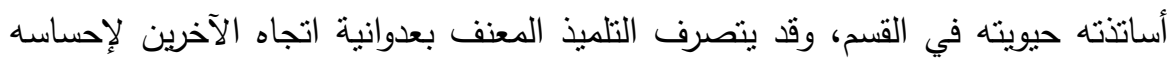
بالخطر وبأنه مهدد معرض للهجوم. 
r. الآثار التعليمية، وتتمثل أساسًا في تدني المستوى التحصيلي للتلميذ والرسوب الدراسي، أو

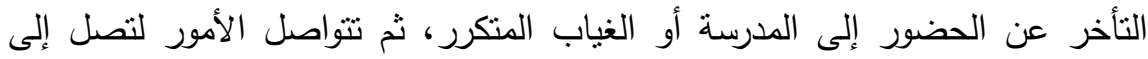

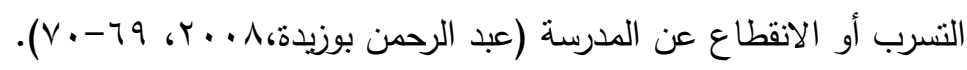

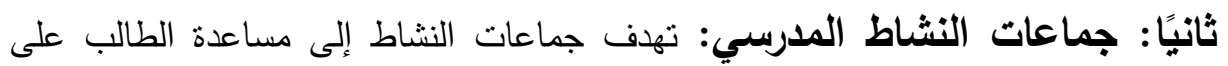
تتمية قدراته الذاتية من خلال عملية التفاعل الدائرة في الجماعات التي ينتمي إليها، بقصد تمكينه من مقابلة النمو الاجتماعي، وتتمية شخصيته الاجتماعية.

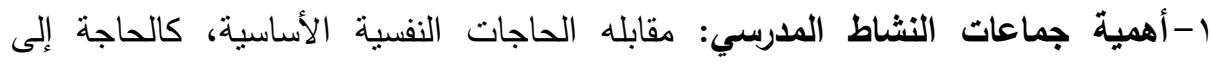
الحماية، والحب والأمن وإثباع الذات، واكتساب مهارات عن طريق الأنشطة، والبرامج

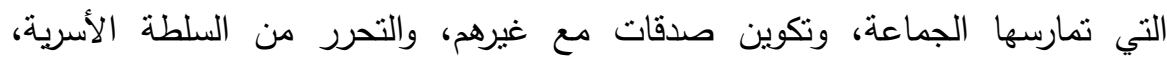

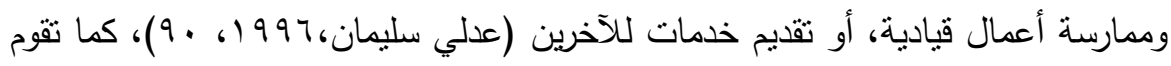

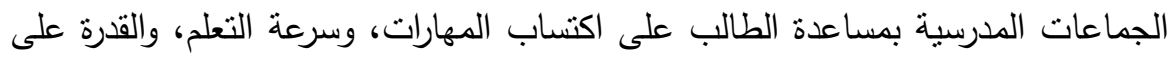
معالجة المشكلات (عصام قمر ، سحر مبروك، ع . . Y، ع (1)). r-خصائص جماعات النشاط المدرسي: الجماعة يجب أن تكون صغيرة الحجم وذللك حتى ميروفي يتمكن الأعضاء من معرفة بعضهم معرفة قوية (Tom Douglas,2000, 33)

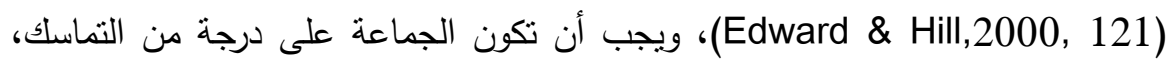
ولها هدف واضح، ويجب أن تكون على درجة من التنظيم الذي يحدد مسئوليات كل عضو ، وواجباته. r-أنواع جماعات النثاط المدرسي: الجماعات الاجتماعية- جماعة الخدمة العامة-الجمعية التعاونية المدرسية- جماعة الهلال الأحمر - جماعة الرحلات-جماعة الأنشطة والهوايات.

\section{الإجباءايت المنهجية للدواسمة}

نوع الدراسةة: تتنمي هذه الدراسة إلى الدراسات الوصفية التحليلية المقارنة. منهج الاراسة: يعتمد الباحثون في هذه الدراسة على منهج المسح الاجتماعي بالعينة. أدوات الدراسة: اعتمد الباحثون في الدراسة على مجموعة من الأدوات كالأتي:

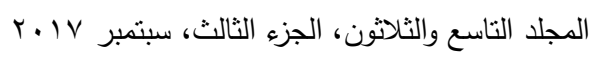


أولاً: استمارة استبيان: لتلاميذ المرحلة الإعداديـة المشاركين في جماعات النشـاط من إعداد

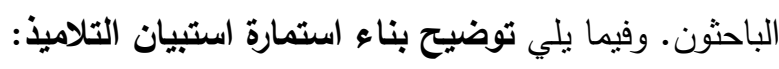

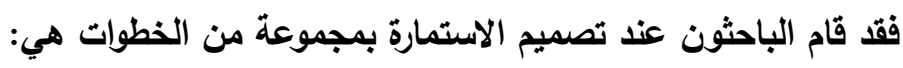

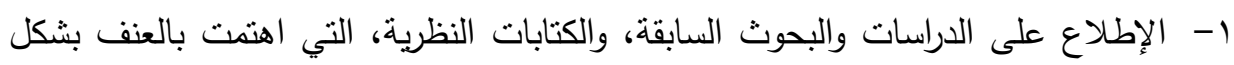
عام والعنف المدرسي بشكل خاص، ودور جماعات النشاط المدرسي. r- تحديد الأسئلة الرئيسية للاستمارة فيما يأتي:

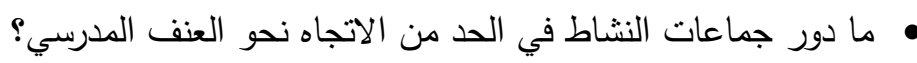

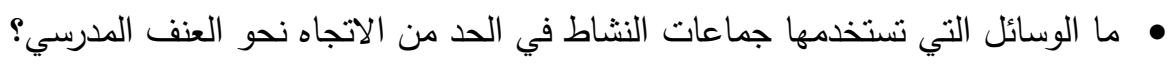

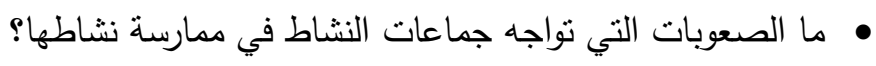
• ما مقترحات مواجهة الصعوبات التي تواجه جماعات النشاط في ممارسة نشاطها؟ ب- صباغة العبارات الدالة على كل مؤشر من الأسئلة السابعة السابقة. وقد راعى الباحثون في تصميم الاستمارة ما يأتي:

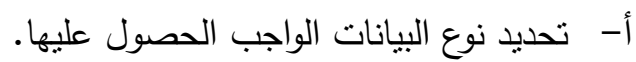

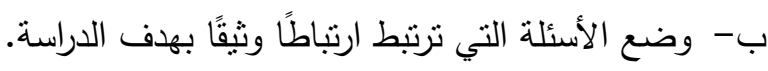
ج- سهولة العبارات ووضوح مضمونها والتأكد من ذلك عند اختبار الاستمارة. د- نَتَاسُبُ الأسئلة مع المستوي التعليمي والثقافي للتلاميذ.

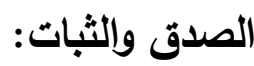

1- الصداق: استخدم الباحثُون نوعين من الصدق وهما: أ- الصدق الظاهري: وهو يتضمن نسب اتفاق المحكمين على أسئلة الاستمارة، حيث نم

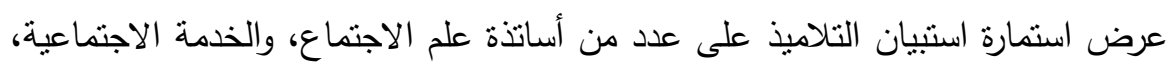

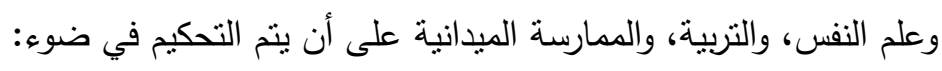
ا ا ـ مدى ارتباط العبارة بكل محور من محاور الدراسة. r r r من حيث صباغة العبارة. r. (ب. من حيث المضمون. 
وبناءً على ذللك فقد تم تعديل الأبعاد العامة للاستمارة، وتم حذف العبارات التي تقل نسبة الاتفاق عليها عن ه^\%، وقد نم حساب نسبة الاتفاق وفقًا لمعادلة (جتمان) التالية:

$$
\begin{aligned}
& \text { عدد مرات الاتفاق }
\end{aligned}
$$

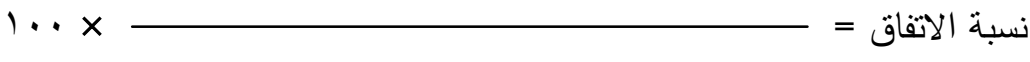

$$
\begin{aligned}
& \text { عدد مرات الاتفاق + عدد مرات الاختلاف }
\end{aligned}
$$

ب- الصدق الإحصائي: نم حساب الصدق الإحصائي بأخذ الجذر التربيعي لمعامل ثبات

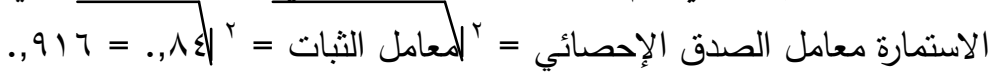

وقد استفاد الباحثون من إجراء عمليتي الصدق في إلغاء بعض العبارات، وإعادة صياغة بعضها الآخر بما يتلاءم مع أهداف الدراسة.

r- الثبات: قام الباحثون بحساب معامل ثبات الاستمارة، باستخدام طريقة إعادة الاختبار

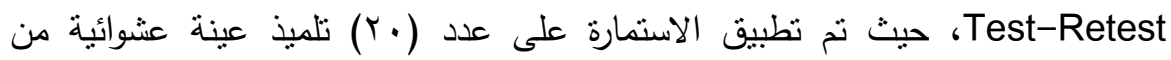
مجتمع مشابه لمجتمع الدراسة، ثم تم إعادة تطبيقها على نفس العينة بعد فاصل زمني (10) يوم أي بواقع أسبوعين بين التطبيق الأول والثاني، وقد قام الباحثون باستبعاد البيانات الأولية، وتم استخدام معامل ارتباط بيرسون، لقياس درجة الارتباط بين التطبيق الأول والثاني. جدول رقم(1) : يوضح ثبات استمارة استبيان الطلاب وصدقها

\begin{tabular}{|c|c|c|c|c|}
\hline مستَوقى الدلالة & الصعامل & 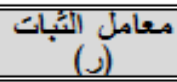 & البعد & a \\
\hline دال י.,. & $.9 T \wedge$ & $\cdots \lambda q_{1}$ & دور جماعات الثناط & ' \\
\hline בוل י... & $\because 94 \mathrm{~V}$ & .177 & الوساثل الثىى تستخذمها جماعات النشاط & $r$ \\
\hline בال +.,. & .945 & $\cdots \mathrm{NT}$ & الاستماردّ كکل & \\
\hline
\end{tabular}


ثانيًا: دليل مقابلة: وذلك مع عينة من الأخصائيين الاجتماعيين والمشرفين على جماعات

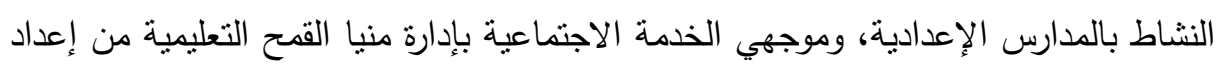

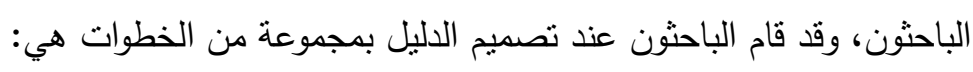

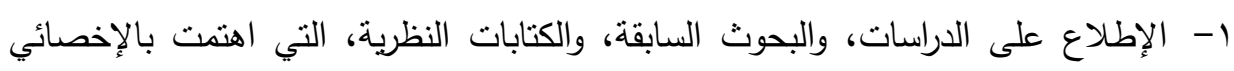
الاجنماعي الذي يعمل مع جماعات النشاط المدرسي والخبراء في المجال. r- تحديد الأبعاد الرئيسية للاليل فيما يأني:

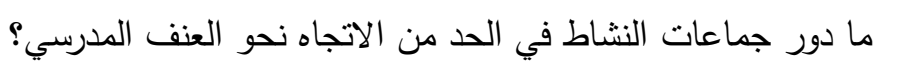

• ما الوسائل التي تنتخدمها جماعات النشاط في الحد من الاتجاه نحو العنف المدرسي؟

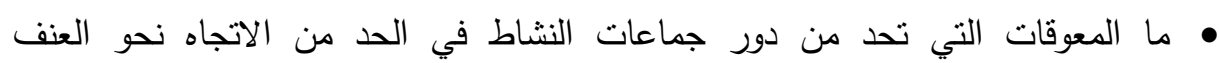
المدرسي؟ • ما مقترحات الحد من المعوقات الني تحد من جماعات النشاط في الحد من الاتجاه نحو العنف المدرسي؟ ماتج

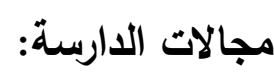

أ- المجال المكاني: تم تطبيق الدراسة الميدانية على عدد (ع) مدارس إعدادية بمدينة منيا القمح، مقسمة مدرسنين ذكور (الألفي الإعدادية بنين، الثربيني الإعدادية بنين)،

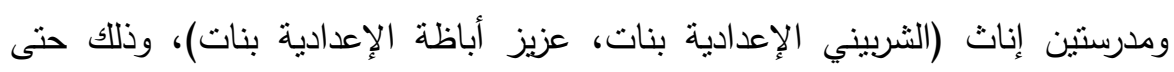

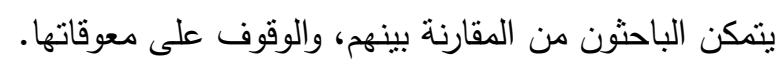

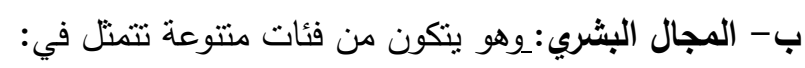

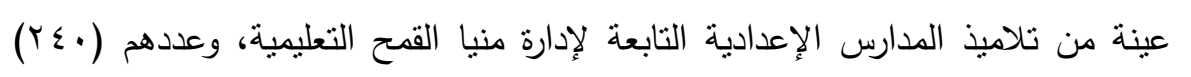
مفردة من الذكور والإناث.

حصر شامل للإخصائيين الاجتماعيين والمشرفين على جماعات النشاط، وقد بلغ عددهم (Y (T)، بواقع أخصائي أو مشرف واحد لكل جماعة من كل مدرسة من المدارس الإعدادية

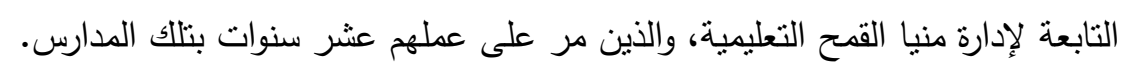

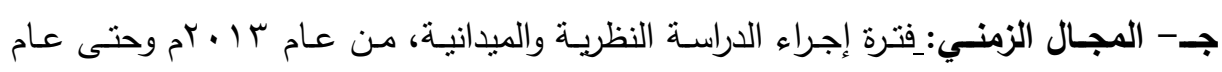
$\cdot \rho^{r} \cdot 1 \mathrm{~V}$

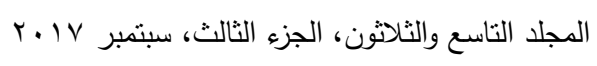


أساليب المعالجة الإحصائية: استخدمت الباحثون مجموعة من الأساليب الإحصائية المناسبة لتحليل البيانات التي تتفق مع طبيعة البيانات وذلك باستخدام برنامج (SPSS) لحساب (معامل ارتباط بيرسون، Chi-Square Tests).

\section{in:}

جدول رقم(ץ): الفروق بين متوسطات درجات مفردات النوع (ذكر - أنثى) فيما يتصل بدور

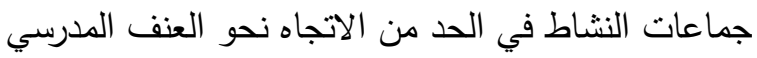

\begin{tabular}{|c|c|c|c|c|c|c|c|c|}
\hline \multirow[b]{2}{*}{ 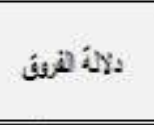 } & \multirow{2}{*}{$\begin{array}{l}\text { ris }{ }^{2}+\frac{1}{4} \\
\text { Chi- } \\
\text { Square }\end{array}$} & \multicolumn{2}{|c|}{ لمبالم } & \multicolumn{2}{|c|}{ 3i } & \multicolumn{2}{|c|}{ si } & \multirow[b]{2}{*}{ (1) } \\
\hline & & $\%$ & $z$ & $\%$ & $g$ & $\%$ & $z$ & \\
\hline غِرِ فلة & $0,1+1$ & 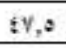 & 118 & $t \lambda, t$ & 24 & $i n, i$ & i1 & 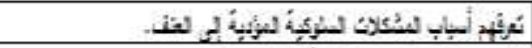 \\
\hline غرِ دلة & . vy: & $\mathrm{r} r, \mathrm{~A}$ & oy & $\pi 1,1$ & $\pi$ & $\pi$ & Fi & 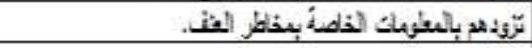 \\
\hline غِرِ دلة & $1,10 i$ & $\$ 1, \gamma$ & $1 \ldots$ & $\pm 2,1$ & 21 & $r y, t$ & is & 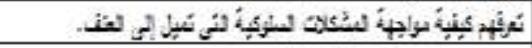 \\
\hline غِرِ دلة & $\cdot, 1 \pm A$ & $r t, r$ & $2 \mathrm{~A}$ & $\pi, 3$ & 14 & $r+1$ & $r 9$ & 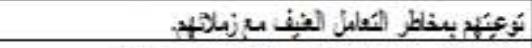 \\
\hline$(\cdot,+1)$ (1) & $14,+44$ & $11, y$ & $T A$ & $r, Y$ & $t$ & $1 A,+4$ & it & 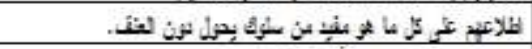 \\
\hline غِر دلة &., 110 & 16,7 & ro & 10,3 & IY & $1+, y$ & in & 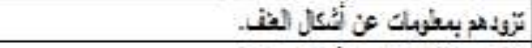 \\
\hline ثِر يلة & $t,+2 t$ & 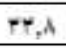 & A1 & $\mathrm{rA,2}$ & $t r$ & $79, \mathrm{~A}$ & +4 & 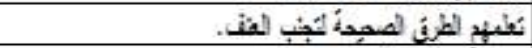 \\
\hline غخرِ دلة &., $9+3$ & 10 & $m$ & $1 Y, 8$ & 19 & $1 \%$ & iv & 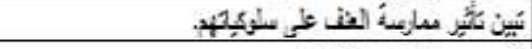 \\
\hline 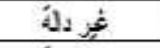 & $1,9 \cdot 4$ & $+1,4$ & $y_{0}$ & $r_{0,1}$ & +4 & $\mathrm{TV}, \mathrm{O}$ & $m$ & 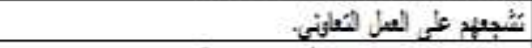 \\
\hline خير فئة & $1,4 \mathrm{Vt}$ & $\mathrm{rA}, \mathrm{r}$ & in & $\pi+4$ & $\mathrm{ri}$ & $+\tau, 1$ & : & 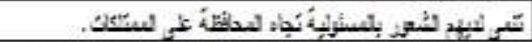 \\
\hline 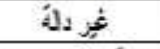 & $1, + \pm A$ & 19,1 & 4 & $\pi$ & r: & $11, \AA$ & $\pi$ & 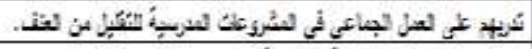 \\
\hline 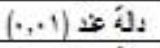 & i,itr & $r t, i$ & AT & $t 4,1$ & $\mathrm{tY}$ & $T Y, O$ & $m$ & 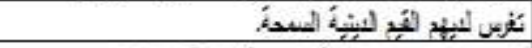 \\
\hline 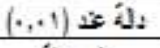 & $Y, \pi 10$ & $1 \mathrm{~A}, \mathrm{r}$ & $i t$ & $r o, v$ & iA & $1 \pi, 5$ & 19 & 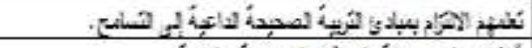 \\
\hline غِر دلة & $1, A \pm Y$ & $r, r$ & $2 i$ & $19, \pi$ & $n$ & $\pi, y$ & $r 8$ & 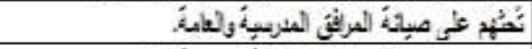 \\
\hline غِر دلة & $\cdot, 1 \cdot 9$ & $2 \mathrm{~A}, \mathrm{r}$ & $i t$ & $1 Y, \xi$ & 19 & 19,1 & ro & 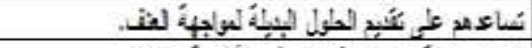 \\
\hline خِر دلة & $\cdot, t:$. & $r t, i$ & 29 & $+1,7$ & rit & $\pi, 4$ & $r$. & 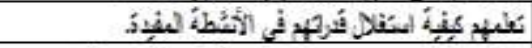 \\
\hline غُرِ دلة &., $\mathrm{riA}$ & 11,4 & $\mathrm{TV}$ & $1 ., 1$ & 11 & $1 \pi, 5$ & 19 & 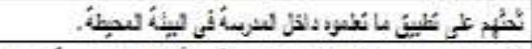 \\
\hline غير فلة & 1, vo. & $1 \pi, 0$ & $r$. & 10,1 & iv & 9,9 & ir & 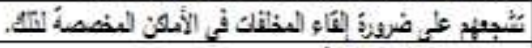 \\
\hline غِرِ لة &., 174 & $r i, r$ & ir & $T Y, 2$ & $r$. & $T_{0, t}$ & $r$ & 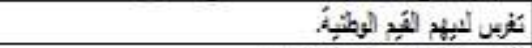 \\
\hline ثخر فلة & .,ors & $T \cdot, \mathrm{A}$ & o. & $\pi, 9$ & to & 19,1 & to & 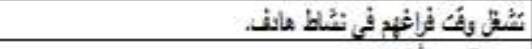 \\
\hline 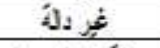 &.,$+\mathrm{ri}_{1}$ & $\mathrm{rA}, \mathrm{A}$ & 39 & $r 9,8$ & ri & $r A, r$ & ry & 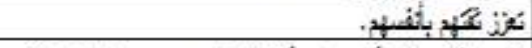 \\
\hline (.,.1) & 4,34 & $\pi, 1$ & $2+$ & $+\mathrm{A}, \mathrm{s}$ & +1 & $17, \AA$ & $\pi$ & 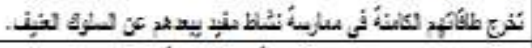 \\
\hline غيز دلة &.,.$y_{0}$ & $r i, Y$ & it & $T Y, 2$ & t. & 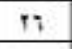 & $+i$ & 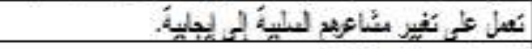 \\
\hline 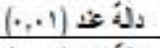 & Y,TIT & $1 \%, 0$ & it & $r t, 4$ & $\mathrm{rY}$ & 11,0 & 10 & 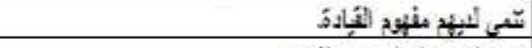 \\
\hline 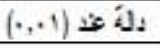 & i, ז & $r+, 9$ & va & $\pm 1, \pi$ & to & $\pi$ & $+i$ & 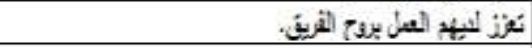 \\
\hline - & - & - & rt. & - & 1.4 & - & $1+1$ & 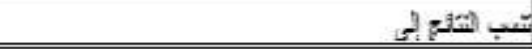 \\
\hline
\end{tabular}


يتبين من الجدول السابق، الخاص بالفروق بين متوسطات درجات مفردات النوع (ذكر -

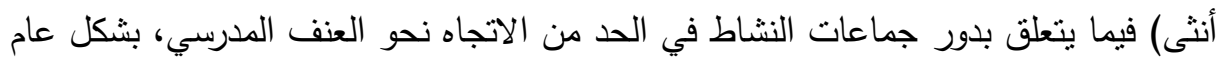

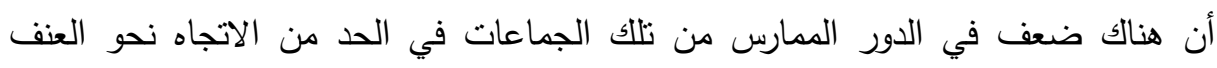

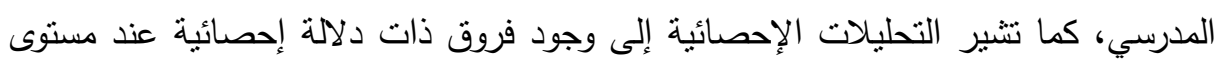
معنوية (1., (·) فيما يتعلق: (اطلاعهم على كل ما هو مفيد من سلوك يحول دون العنف،

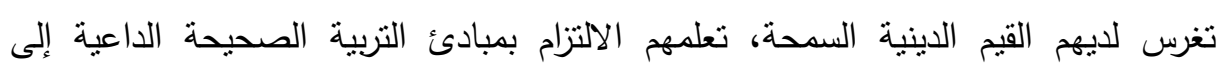

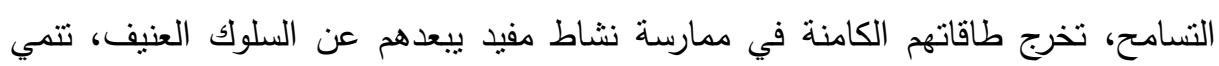
لديهم مفهوم القيادة، تعزز لديهم العمل بروح الفريق).

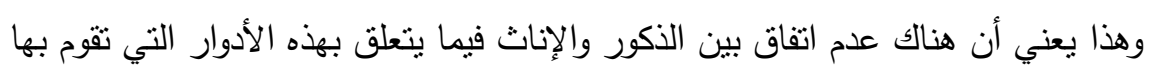

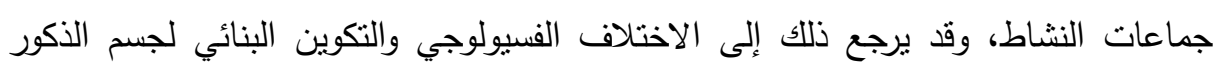

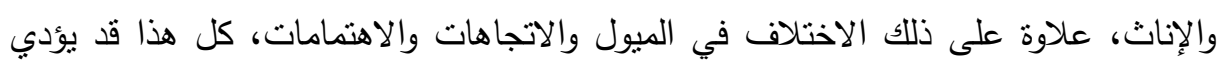
إلى الاختلاف في طبيعة بعض ممارسة أنشطة الجماعة.

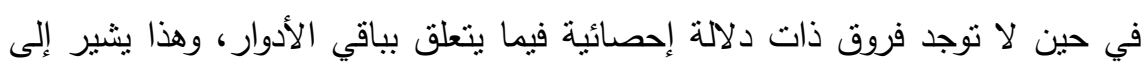

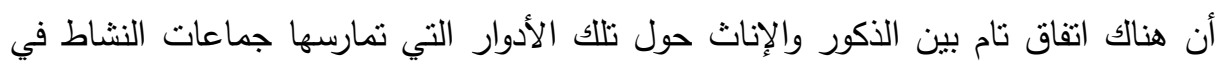
الحد من الاتجاه نحو العنف المدرسي على الرغم من ضعفهام الملحوظ.

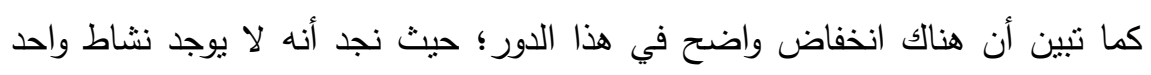

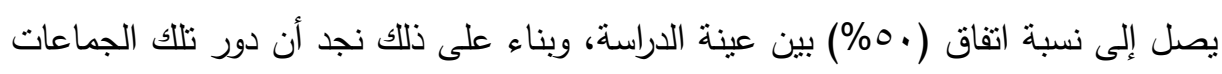
ضعيف ولا يتتاسب مع حجم قضية العنف بشكل عام والمدرسي بشكل خاص، لذافئ لذا ينطلب اهتمام جماعات النثاط بزيادة الجانب المعرفي عند التناميذ تجاه العنف، ومحاولة تصحيح المعلومات والمعارف والحقائق غير الصحيحة تجاه العنف، ومحاولة غرس القيم الايجابية والدينية الصحيحة والتي تحث على الحد من الاتجاه نحو العنف بشكل عام والمدرسي بشكل التهل خاص؛ حيث أن مشاركة التلاميذ في نلك الأدوار التي تقوم بها جماعات النشاط النداه المدرسي في الحد من الاتجاه نحو العنف المدرسي يتمشى مع ما يجب مراعاته عند تكوين جماعات النشاط بالمدرسة، وما يهدف إليه نشاط تلك الجماعات؛ حيث بهدف إلى تدريبهم عمليًا، وذلك 
عن طريق التعرف على الإمكانات المادية والبشرية، والمشكلات والقضايا المنتشرة، وإكسابهم خبرات ومهارات واتجاهات إيجابية. وقد يتفق ذلك مع دراسة (طلعت منصور وآخرون-r...r)، دراسة (سهام عبد الحميد

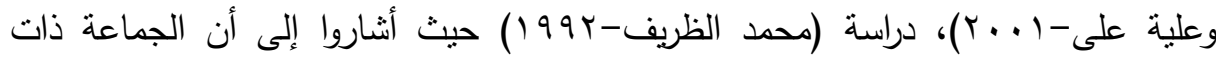

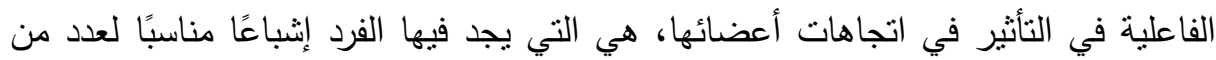

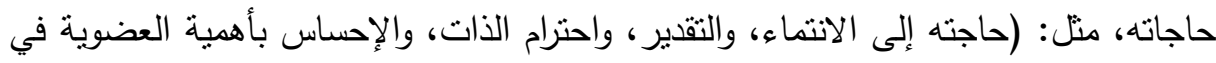

$$
\text { الجماعة.... وغيرها). }
$$

جدول رقم(ץ): الفروق بين منوسطات درجات مفردات النوع (ذكر - أنثى) فيما يتصل بالوسائل التي

\begin{tabular}{|c|c|c|c|c|c|c|c|c|}
\hline \multirow{2}{*}{ الفروق } & \multirow{2}{*}{$\begin{array}{c}\text { قيمة }{ }^{\prime} \\
\text { Chi- } \\
\text { Square }\end{array}$} & \multicolumn{2}{|c|}{ إجمالي } & \multicolumn{2}{|c|}{ أنثي } & \multicolumn{2}{|c|}{ ذكر } & \multirow{2}{*}{ الوسائل } \\
\hline & & $\%$ & ك & $\%$ & ك & $\%$ & ك & \\
\hline دالة عند & $9,7 \cdot 1$ & $0 \cdot, \varepsilon$ & $|r|$ & $r q, \varepsilon$ & $\varepsilon r$ & 09,0 & $\vee \wedge$ & تتفيذ رحلات ترفيهية \\
\hline غير دالة & ו & $r V, O$ & 77 & $r r, q$ & $r 7$ & $r \cdot, 0$ & $\varepsilon$ & تتفبذ ندوات توعية \\
\hline غير دالة & $1, \leqslant 00$ & $r q, 7$ & $v_{1}$ & $r_{0, V}$ & r^ & $M r, \Lambda$ & $\varepsilon r$ & عن العداد إرشادات توعية \\
\hline غير دالة & ו ו & $r$. & $V Y$ & $r \wedge, \varepsilon$ & r & r, r & $\varepsilon 1$ & 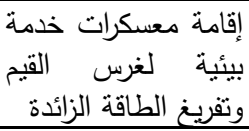 \\
\hline دالة عند & $11,9 \leq 0$ & $r \cdot, \varepsilon$ & $\leqslant 9$ & $r \cdot, r$ & 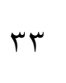 & $M, r$ & 17 & إذاعة المدرسة المشاركين في \\
\hline 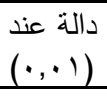 & $11,00 \mathrm{~V}$ & $r r, q$ & 00 & س & ri & $1 \leqslant, 0$ & 19 & فصل \\
\hline دالة عند & $1 r, 1 \cdot 9$ & $r$. & VY & $\varepsilon 1, r$ & $\leq 0$ & $r \cdot, r$ & rV & إقامة $\quad$ مشتروعات البيئة \\
\hline غير دالة & $r, \Sigma Y r$ & $r, r$ & 01 & $r Y, 7$ & $r q$ & $17, \wedge$ & rt & إقامة معارض فنبة \\
\hline $\begin{array}{l}\text { دالة عند } \\
(\cdot) \cdot(\cdot)\end{array}$ & $\varepsilon, \vee \wedge \vee$ & $r v, q$ & $T V$ & $r \varepsilon, q$ & rᄉ & $r r, 1$ & rq & في لوحة الثماء المتمبزين \\
\hline غير دالة & $\cdot, 91 \leq$ & $\lceil\wedge, \wedge$ & 79 & $r_{0, V}$ & $r \wedge$ & $r, r$ & $\varepsilon 1$ & مخاطر العنف توعية عن \\
\hline- & - & - & $r \leq$. & - & 1.9 & - & וTו & تتسب النتائج إلى \\
\hline
\end{tabular}


يتضح من الجدول السابق، الخاص بالفروق بين متوسطات درجات مفردات النوع

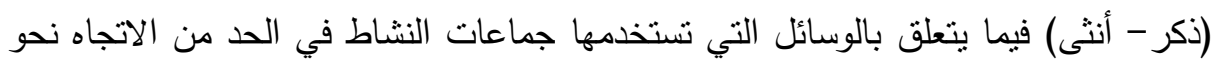
العنف المدرسي، تتير التحليلات الإحصائية إلى وجود فروق ذات دلالة إحصائية عند مستوى معنوية (1,.+) فيما يتعلق: (تنفيذ رحلات ترفيهية، تكريم المشاركين في إذاعة المدرسة، إقامة مسابقة أفضل فصل، إقامة مشروعات نتجير ونظافة البيئة، كتابة أسماء

$$
\text { المتميزين في لوحة الثرف). }
$$

وهذا يعزي عن عدم اتفاق بين الذكور والإناث فيما يتعلق بهذه الوسائل والأساليب التي لتي لتئي

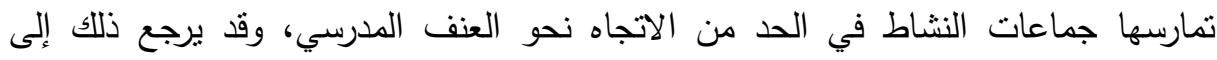
الاختلاف بين الذكور والإناث من حيث الاهنمامات وممارسة النشاط، كما يعكس تأثير كل وسيلة وأسلوب تمارسه جماعات النشاط على الذكور والإناث، أي أن كل وسيلة لها تأثير على لإنى الإناث قد يختلف نأثيره على الذكور.

في حين لا نوجد فروق ذات دلالة إحصائية فيما يتعلق بباقي الوسائل التي تنتخدمها جماعات النشاط، وهذا يشير إلى أن هناك اتفاق تام بين الذكور والإناث حول تلك الوسائل التي تمارسها جماعات النشاط في الحد من الاتجاه نحو العنف الددرسي، حيث يوجد انشتراك فيما بينهم حول استخدام تلك الوسائل والمشاركة من خلالها في النشطة التي تقوم بها جماعات النشاط داخل المدرسة أو خارجها من أجل الحد من الاتجاه نحو العنف المدرسي. كما أوضحت النتائج أن هناك تفاوت واضح بين الوسائل من الول التي تستخدمها جماعات

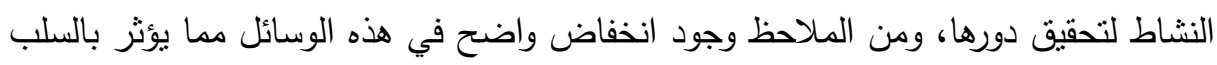

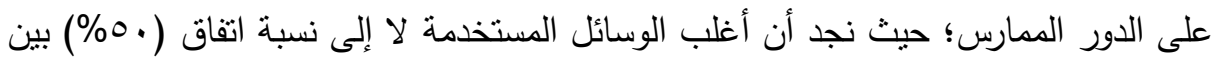

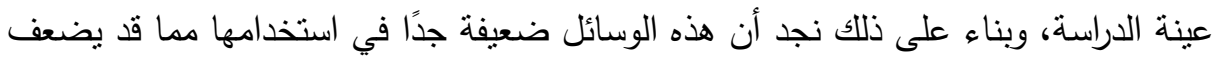

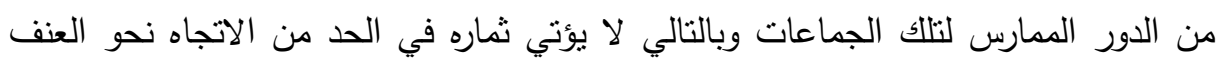

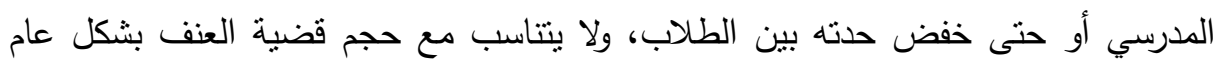

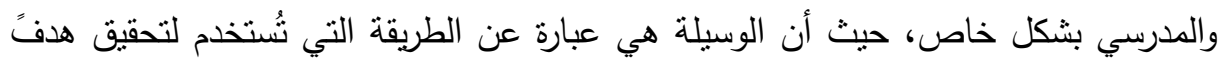

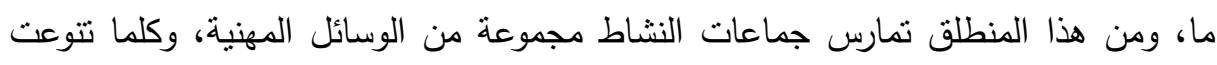
هذه الوسائل والأساليب المهنية، وتعددت، كلما ساعدها في تحقيق أهدافها، وتتفيذ أدوارها

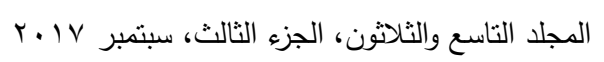


سواء أكانت هذه الأدوار في الجانب المعرفي، أو الجانب الوجداني، أو الجانب السلوكي،

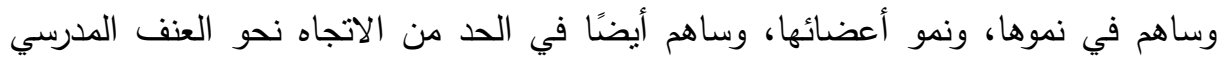

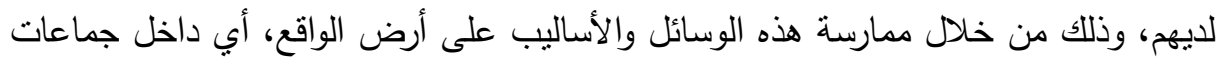

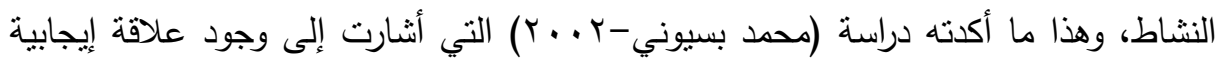

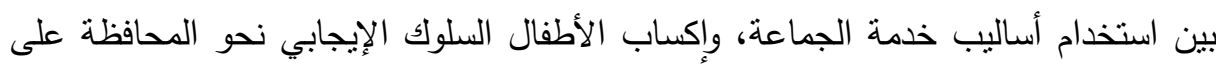

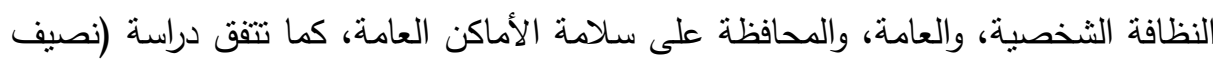
منقريوس-1991 (99) مع ما أنثارت إليه البيانات الميدانية السابقة في أن معظم الأفراد يرغبون

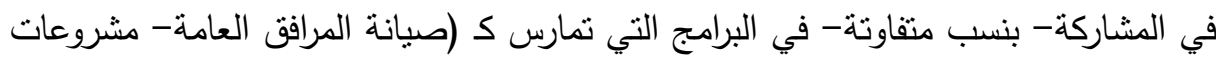

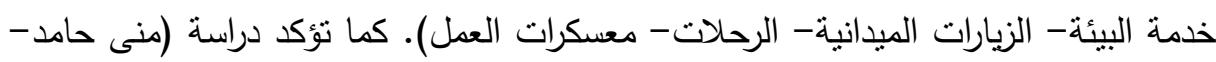
1991 أن قيام الإخصائي الاجتماعي بأدواره مع هذه الجماعات، يتحقق من خلاتل المناقثات، والاجنماعات، والندوات، والأبحاث.

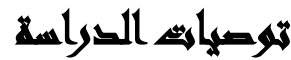

في ضوء نتائج الدراسة وضع الباحثون توصيات تهدف إلى تفعيل الدور الفعلي لجماعات النشاط في الحد من الاتجاه نحو العنف المدرسي وذلك من خلال: ا ـ توعية التلاميذ بالشكلات السلوكية، ومخاطر العنف المدرسي. r. تعريفهم كيفية مواجهة المشكلات السلوكية.

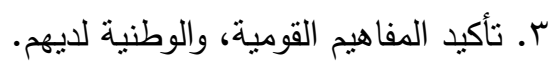

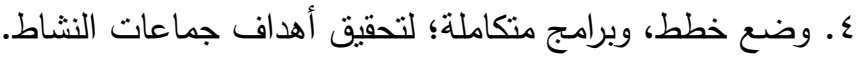

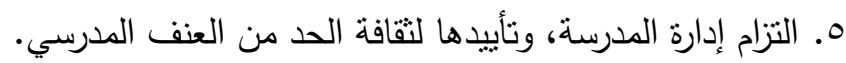
T. تحديد الأدوات المناسبة؛ لقياس حجم ظاهرة العنف المدرسي. V. توفير النشرات، والكتيات، والكتب، التي تشهم في الحد من الاتجاه نحو العنف المدرسي

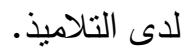


^. إعادة النظر في اختبار الإخصائيين الاجتماعيين بالمدارس، التي تقوم بالإشراف على

$$
\text { جماعات النشاط المدرسي، بحيث لا يقل عن (• (1) سنوات خبرة. }
$$

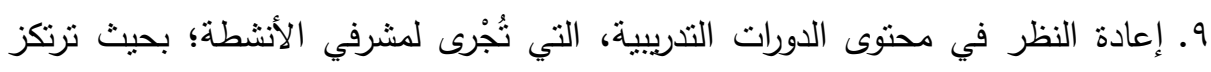
على النظريات الحديثة في الممارسة، واحتوائها على تعلم مشرفي الأنشطة مجموعة من

$$
\text { المهارات، والخبرات اللازمة؛ لتطبيق معايير الجودة. }
$$

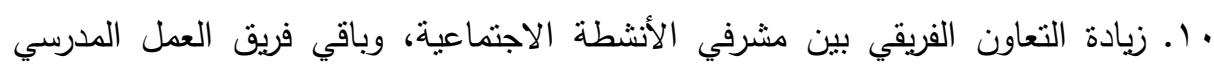

(رواد الفصول، ووكيل للنشاط).

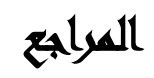

أحمد عاصم عابد الطنطاوي(1991)(: النشاط خارج الفصل وموقف بعض الفلسفات منه،

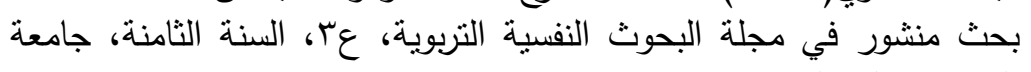
المنوفية، كلية التربية.

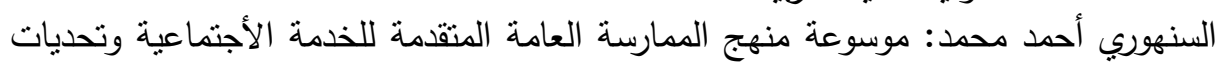

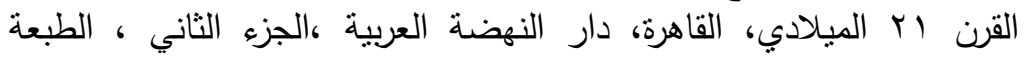

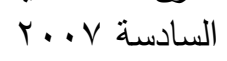

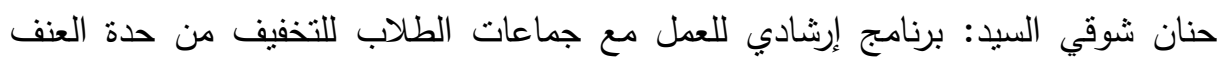

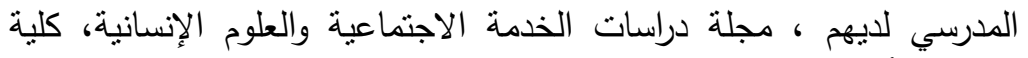

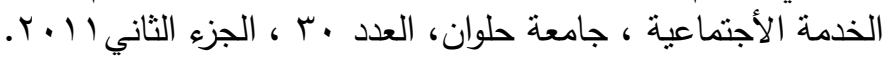

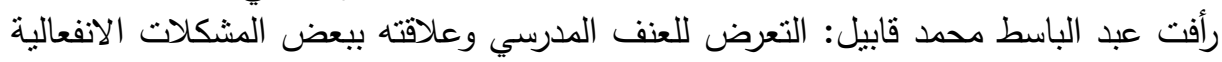

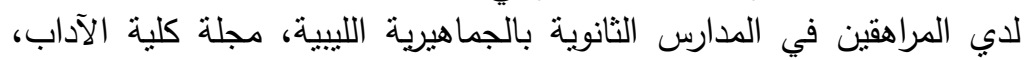

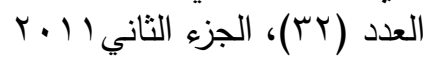

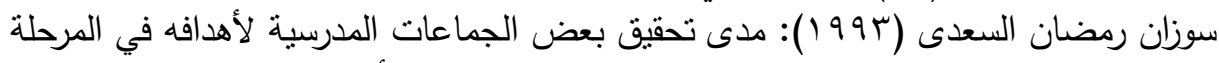

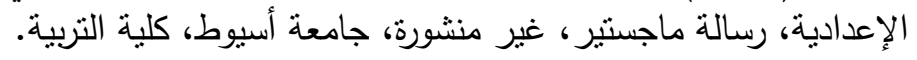

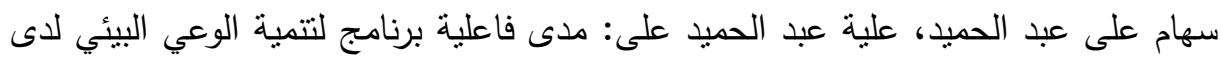

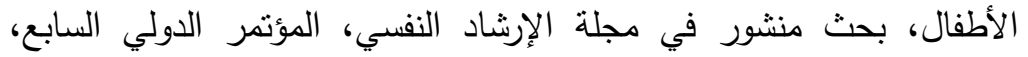

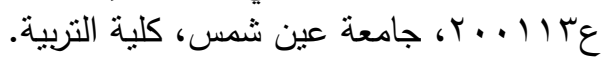

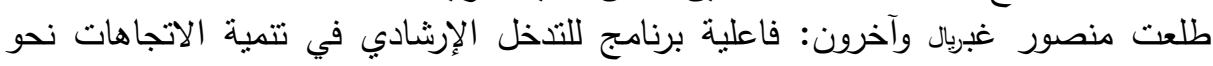

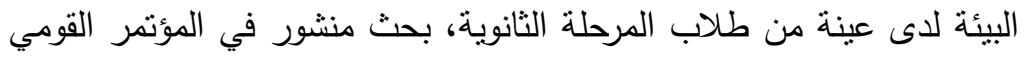

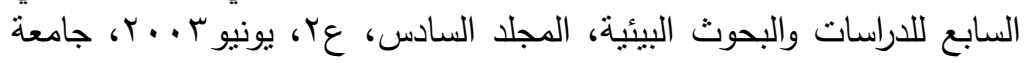
عين شمس، معهد الدراسات والبحوث البيأئية.

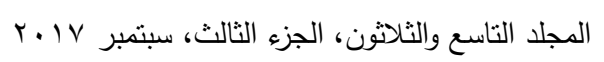




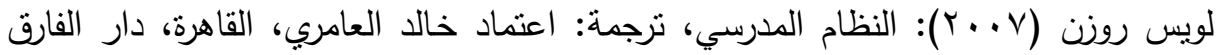

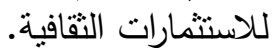

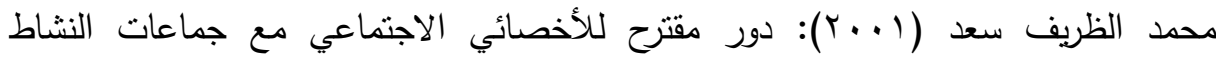

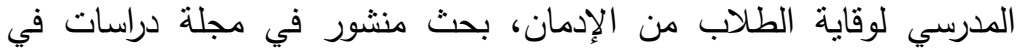

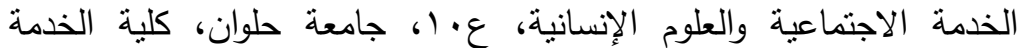

$$
\text { الاجتماعية. }
$$

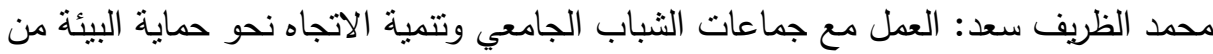

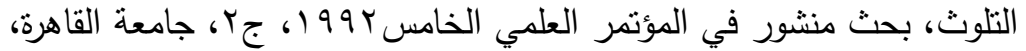
فرع الفيوم، كلية الخدمة الاجتماعية.

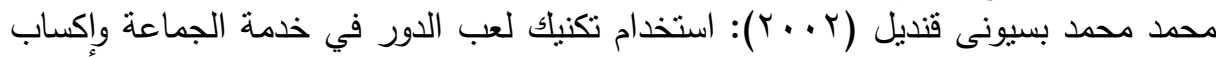
الأطفال السلوك الايجابي نحو البيئة، رسالة ماجستير، غير منشورة، جامعة حلوان، كلية الخدمة الاجتماعية.

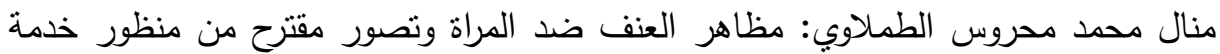

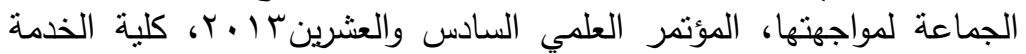

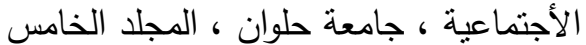

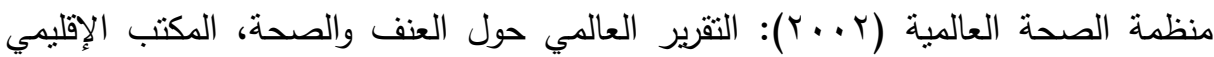

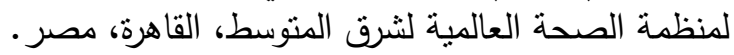

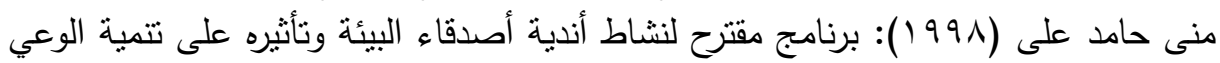

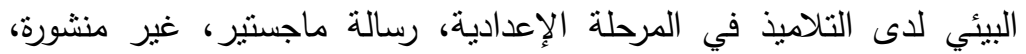

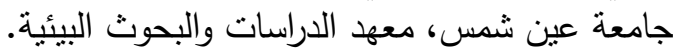

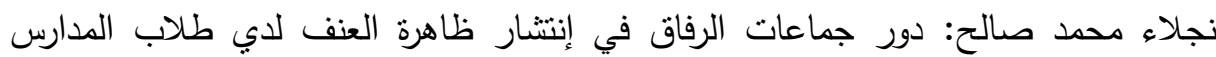

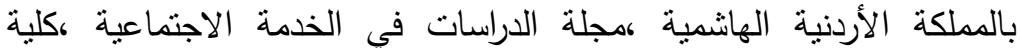

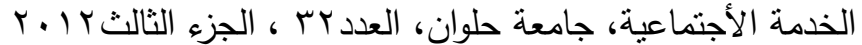

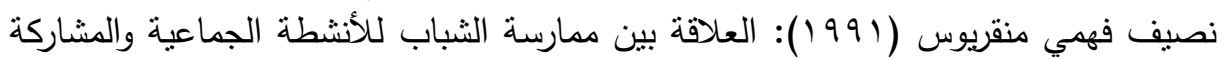

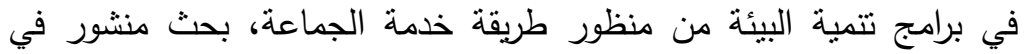
مؤتمر الثباب والتتمية والبيئة، جامعة عين شمس، معهد الدراسات والبحوث البيئية.

Carney, J. Shannon, D. \& Murphy, C. (2005), An Florida elementary school, Journal of school violence, Vol. 4.

among rural middle school students: teacher disconnection as a consequence of violence, Journal of school violence, Vol. 1. Unnever, J. \& Cornell, D. (2003), The Culture of bullying in Middle school, Journal of school violence, Vol. 2.

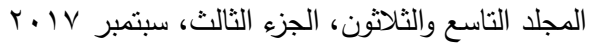


Weinstein, C. (2003), Secondary classroom management, 2nd (Ed) the McGraw-Hill Companies, New York.

\title{
THE ROLE OF ACTIVITY GROUPS IN THE TREND TOWARDS REDUCING OF SCHOOL VIOLENCE
}

\author{
Awad, M. I. ${ }^{(1)}$; Amer, M. E. A. ${ }^{(2)}$; Hani, A. F. ${ }^{(3)}$ \\ and Tohami, Ghada, E. M. ${ }^{(4)}$
}

1) Institute of Environmental Studies and Research, Ain Shams University. 2) Higher Institute of Social Work in Kafr El Sheikh. 3) Institute of Environmental Studies and Research, Ain Shams University 4) Higher Institute of Social Work in Benha.

\begin{abstract}
It is concluded from this study that the activity groups have a role in reducing the trend towards school violence, but it is a weak role and needs a great effort, because it faces many difficulties and problems that hinder these groups to perform their role to the fullest. The study consisted of a sample of (240) male and female students distributed among (4) schools belonging to Minya Al-Qamh Educational Administration. Study on the Social Survey Method A survey questionnaire was used for middle school students participating in activity groups, an interview guide for social workers, supervisors of middle school work groups, and social work supervisors of the Minya al-Qamh Educational Administration. The study showed several results, the most important of which are that the activity groups know the causes of behavioral problems leading to violence (47.5\%). They know how to deal with behavioral problems that tend to be violent (41.7\%). The group also instills religious values by (34.6\%). The results of the study showed that the most practiced methods of activity groups are recreational trips (50.4\%), Establishment of environmental work camps to instill values and discharge excess energy, establishment of afforestation and environmental clean-up projects (30\%), and preparation of awareness guidelines on violence (29.6\%), The study

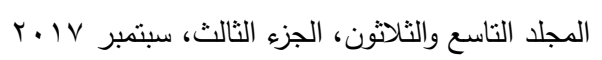


مجلة العلوم البيئية

معهد الدراسات والبحوث البيئية - جامعة عين شمس

found a number of recommendations, including students' awareness of behavioral problems, the dangers of school violence, their definition of how to cope with behavioral problems, the confirmation of national and national concepts, plans and integrated programs; Pamphlets, brochures and books that contribute to reducing the trend towards school violence among pupils. 